\title{
Implications of observing and writing field notes through different lenses
}

\author{
This article was published in the following Dove Press journal: \\ Journal of Multidisciplinary Healthcare \\ 8 April 2015 \\ Number of times this article has been viewed
}

\author{
Ragnhild Hellesø' \\ Line Melby' \\ Solveig Hauge ${ }^{2}$ \\ 'Department of Nursing Science, \\ Institute of Health and Society, \\ Faculty of Medicine, University of \\ Oslo, Oslo, Norway; ${ }^{2}$ Faculty of \\ Health and Social Studies, Telemark \\ University College, Porsgrunn, \\ Norway
}

Background: From a philosophy of science perspective, the literature has posited that different research approaches influence field studies. Studies addressing interdisciplinary research have focused on the challenges of organizing and running interdisciplinary teams, cultural differences between and within disciplines, and constraints in conducting interdisciplinary research. Studies exploring and discussing the process and outcome of transferring observations to notes from an interdisciplinary point of view are not identified. The aim of this paper is to explore the characteristics of field notes created by researchers representing different disciplines and experiences.

Methods: A case study using a modified dynamic observation method was employed. The analyses were initiated by a researcher who had not been involved in the data collection. The field notes were analyzed using three main steps.

Results: The structures of both researchers' field notes were characterized by similarities in their descriptions, but the notes' foci and analytical levels differed.

Conclusion: The findings contribute new insights concerning the execution of interdisciplinary observational studies. Our findings demonstrate that entering the field with different lenses produced richer and more varied data, providing a broader platform from which to discuss and interpret a study's findings. From a theoretical point of view, the findings enable a more nuanced discussion and a conceptual elaboration regarding how observational approaches should be pursued in future studies. On a practical level, the findings show that even if the researchers agree on what the overall focus in the observations should be, differences can occur in both their focus and analytical level throughout the study.

Keywords: field study, observational study, interdisciplinary lenses, interpretation, home care nursing

\section{Introduction}

The catchphrase "interdisciplinary research" has become a mantra that provides the generative processes of harvesting, capitalizing, and leveraging from multiple areas of expertise. ${ }^{1}$ According to Clarke et al, "an interdisciplinary approach seeks to open up the kinds of questions to be addressed not just employ different methods". ${ }^{2}$ The nature of interdisciplinary research has evolved over recent decades as researchers aim to understand phenomena from various angles. Studies addressing interdisciplinary research have mostly focused on the challenges in organizing and running interdisciplinary teams in which different perspectives and approaches meet, ${ }^{2,3}$ in cultural differences that exist between and within disciplines, ${ }^{4}$ and in facilitators for and constraints on conducting collaborative interdisciplinary research. ${ }^{5}$
Correspondence: Ragnhild Hellesø Department of Nursing Science, Institute of Health and Society, Faculty of Medicine, University of Oslo, PO Box II 30 Blindern, 0318 Oslo, Norway Tel +4722850566 Fax +4722850570 Email ragnhild.helleso@medisin.uio.no 
However, studies exploring and discussing the process and outcome of transferring observations to notes while conducting field studies from an interdisciplinary point of view in nursing science are not identified. This became apparent when we - who had different educational backgrounds as well as divergent experiences while performing field observations - planned for a field study in home health care. Our assumption was that different researchers' interpretive perspectives would influence the form, content, and genre of their notes. Field study represents a qualitative approach wherein reality is socially constructed and lenses represent varied viewpoints throughout all the phases of a research process. ${ }^{6}$ Field studies are considered to have a subjective underpinning and thus bring up issues related to the trustworthiness of the study. Thus, researchers should be aware of the ways in which their lenses might impact the content and perspectives of their field notes.

\section{Background}

Taking field notes is a common method of documenting observations, ${ }^{7}$ and the practice is well acknowledged within qualitative research. ${ }^{8}$ Peshkin emphasized the need to be aware of the researcher's perspectives and, therefore, which topics tend to draw focus. He states, "we are never free of lenses through which to perceive". ${ }^{9}$ Age, religion, profession, and social class combine to produce viewpoints that affect researchers' points of view. Wolfinger similarly states that field notes will always be influenced by the researcher's expectations and tacit knowledge. ${ }^{10} \mathrm{~A}$ more or less tacit "significance filter" is applied, and each observer is constrained by the individual's ability to observe, with the result that some events in a setting are noted, while others are not. ${ }^{8}$ Note-taking may also represent a step in "the process of moving from the informal and intuitive knowledge that comes with experience and observation". ${ }^{11}$ In addition, observers who have different knowledge and skills may influence the focus in the observations. ${ }^{2}$ Taking field notes raises fundamental questions regarding what the researcher chooses to observe and write. Thus, some events may be in the background and others in the foreground; however, the focus may change during the phases of observation, which is expected to be reflected in the notes taken.

According to Mulhall, two distinct positions can be taken when conducting observations in field studies, broadly reflecting positivistic and naturalistic paradigms. ${ }^{12}$ Traditionally, the term "paradigm" is associated with Kuhn's term "paradigm shift". ${ }^{9}$ However, Denzin and Lincoln ${ }^{13}$ use the term "paradigm" more pragmatically and use it to describe diversity between a wide range of research traditions and philosophical positions labeled positivism, post-positivism, critical theory, and constructivism. The diversity in the range of paradigms is how they position themselves in their views and approaches to the relationship between reality and knowledge production and knowledge accumulations. The overall debate of approaches reflects epistemological inquiries regarding the nature of scientific activity and beliefs about how knowledge is produced. ${ }^{14}$

The various positions and approaches are important for how we consider the relationships between the observer, the observed field, and the researcher's notes. Taking into account the wide range of scientific positions, we do not aim to clarify all positions for the implications they have for conducting observations. But using Mulhall's ${ }^{12}$ two contrasting positions illustrates the implications on the practical level. The observer who relies on a positivistic tradition emphasizes "that the field represents a natural entity, out there, which needs to be objectively described by the observer". ${ }^{12}$ This researcher tries to take a detached role from the field being observed in an attempt to remain objective, claiming that such researchers describe with exactitude what they see and what they sense.

In the naturalistic view, one considers the field to be something that we construct throughout the different phases of field study. The main tenet is that "it is impossible to separate researcher from researched" 12 and that field notes become a part of an interpretive process. ${ }^{15}$ Another distinction is the extent to which the researchers use the first or third person in writing their field notes. First-person narrative presents a more personal account than writing in the third person, which in turn demonstrates a more objective approach to the field. ${ }^{16}$ This distinction coincides with the views of Van Maanen, who states that the "realists" take an impersonal stand, looking at themselves as a channel between the field and the reader. ${ }^{17}$ This approach is one of the three different forms that he identified for taking field notes. The second is the "confessional" style, in which researchers include their own personal experiences and methodological confessions. Both the realist and confessional writer believe that they themselves have the authority to be the field interpreter. The third form is the "impressionist" style, in which evocative notes are written. The researcher writes personal stories, which the reader can use to interpret the field. Combinations of the three styles are possible in the note-taking.

Peshkin suggests four different strategies for categorizing observations to determine the form of the field note: addressing everything that happens, recording non-events, 
noting paradoxes, and recording key problems confronting the group. ${ }^{9}$ Wolfinger ${ }^{10}$ suggests two strategies. In the first, called "salience hierarchy", researchers record events that interest or intrigue them (ie, typical anomalous situations). The second is to take "comprehensive notes" continuously. ${ }^{10}$ The second strategy is similar to Peshkin's strategy of recording non-events.

Furthermore, Wolfinger ${ }^{10}$ highlights that practical considerations involved in taking field notes are neglected in the research literature. In this study, we seek to open up this neglected window, aiming to render transparent the deliberations that are made throughout a field study. Even if different strategies for conducting field notes are suggested, the notion seems to be that the field researcher positions themselves within a positivistic or naturalistic approach. Our assumption, before conducting the study, relied on this contrasting understanding, further demonstrating the ways in which a field researcher's view of the field will influence the form, content, and genre of their notes. The overall aim of this paper was to explore the implications of researchers entering the same field when they represent different lenses. The specific research question was: what are the characteristics of the field notes produced by researchers with different educational backgrounds and divergent experiences with conducting field studies?

\section{Methods}

The study from which this paper departs is part of a field study of home health care nurses' information practices wherein data from observations, interviews, documents, and questions were utilized for the analysis. The overall aim of the project was to develop knowledge regarding home care nurses' information practices and digital communication of information in their collaborations with general practitioners and hospital providers. For the purpose of this paper, we chose a case study design for our investigation. A case study is useful when researchers aim to investigate meaningful characteristics of real life and can focus on few individuals. ${ }^{18}$ Within the flexible nature of a case study, we applied a modified dynamic observation method, which means, according to Tjora, that the observer moves and works together with the people who are being observed. ${ }^{19}$ The aim of the observations was to obtain detailed knowledge and insight into how home care nurses work during their daily rounds visiting their patients and, in particular, to obtain insight into how they perform their information work. Topics and themes for guiding the observations were developed. This strategy coincides with Hammersley and Atkinson's statement that it is impossible to take notes without having some idea of what you are investigating. ${ }^{20}$ However, we did not create a uniform style of note-taking before making observations.

\section{Setting and participants}

The study was conducted in three differently sized Norwegian municipalities, which were organized into nine independent units to ensure maximum variation in our observations. ${ }^{7}$

The first and second authors (RH and LM) conducted the observations. The first, a nurse researcher, was inexperienced in conducting observations but had a few years' experience as a nurse in the home care setting more than 20 years ago. The second, a researcher in sociology, had significant experience in field studies as part of several projects, including observations in hospitals, but had no knowledge of the home care nursing field. The sociologist was trained to enter the field with an open mind and not be constrained by any predefined research question. The nurse researcher was concerned that she would not be "naïve" enough and would jump to conclusions too quickly early in the observation phase and, thus, miss important information from the nurses' information work. For example, she knew from previous experience that home care nurses use lists of the patients' medication regimes. Therefore, she prepared herself to keep these preconceptions in mind. She carefully considered the situations that she might take for granted and that could occur during the observations and would, therefore, prevent her from obtaining an in-depth understanding of the phenomenon under investigation.

\section{Data collection}

We followed nurses during their visits to patients receiving health care in their homes. A day in the field typically started with our arriving at the home care unit's office in the morning and each of us being assigned to follow a nurse throughout the day. The nurses were informed about the project's aim ahead of our arrival, but were not given information about our backgrounds.

The most common way to start the day was an initial morning meeting, where we observed all of the staff together as they coordinated their work and delegated tasks before heading out to the patients' homes. Together with the assigned nurse, we visited patients in their homes. All observations were thus conducted separately. The number of visits for which we followed the nurses per day varied from three to nine. To document our observations, our main technique was to write field notes, but we also collected documents and took photographs. Both observers tried to take initial notes either during the nurse visit or in the car between the visits. 
However, sometimes information was added at the end of the day because there was insufficient time during or between the visits to describe everything. We also considered ethical issues in the patients' homes. Some patients wanted to talk to us, making it inappropriate to take notes.

The sociologist noted that she did not pay much attention to the themes in the observation guide when she entered the field. Her previous experience conducting observations, her training, and perhaps also her personal disposition led her to fall back to an open approach in which anything that caught her interest was documented in the field notes. However, an experience from her previous observations is that writing satisfactory descriptions of what happens in the field requires her to be as detailed as possible about the individuals she is observing. The nurse researcher initially chose to rely on the observation guide during the observations as a reminder of the study's focus. However, as time passed, she recognized that she broadened her modes of observation because other topics occurred to her. For instance, she started to reflect on how patients with long-term conditions live at home and manage their daily lives being dependent on health care personnel.

The observations were performed over 9 months (85 hours) at 97 homes from June 2011 to February 2012. The field notes totaled 49 pages.

\section{Data analysis}

The analytical approach was inspired by the descriptions of qualitative research. Qualitative analytical procedure should be systematic and transparent and should be developed in accordance with the research question, theoretical perspectives, and characteristics of the data. ${ }^{21}$ Based on this main understanding, we developed an analytical procedure in three main steps.

The first step of the analysis built upon a list of themes that were agreed upon based on the literature. We wanted to investigate whether the field notes differed in their structure: specifically, the difference in their lengths and amounts of detail as well as the ways in which the observers' interpretations were written and formulated, which terms were used, and what themes appeared when analyzing the notes inductively. In other words, we explored the characteristics of the notes. The preliminary findings from the initial analysis revealed new questions for further analysis.

In the second step, we conducted a more detailed examination of the field notes to deepen our understanding of the themes that developed from the first reading. We investigated which perspective each researcher had in the foreground throughout the field notes. Furthermore, we noted how the researchers positioned themselves in the notes and how the themes in the field notes addressed and reflected the descriptions of everything that was observed versus the descriptions of specific events that struck the observers as noteworthy. This approach gave us an impression of the similarities and differences in the field notes, which were marked as possible themes. In this process, we developed the main themes. For example, we identified that either the nurse or the patient was in the foreground in the notes. This was further analyzed to become the theme "variety in the field notes" focus".

In the third step, an overall reading to clarify and validate our main themes was conducted. This was a back-and-forth discussion in which all authors participated.

\section{Rigor}

The researchers who conducted the field study sent their notes to a research assistant who facilitated the notes for analysis. The preparation was to anonymize the notes by deleting all information which could identify who the researcher was. The two datasets were labeled "Researcher A" and "Researcher B".

The third author $(\mathrm{SH})$ received the anonymized notes and conducted the first phase of the analysis. This author was chosen for this task because she had extensive experience in field studies in nursing homes. She had not been involved in the project or the other authors' previous discussions before entering the field. She was blinded as to who wrote the field notes throughout the entire analysis process.

\section{Ethics}

The main project was reported to the regional ethical committee and to Norwegian Social Data Services. Access to the field was negotiated and approved through leaders in the municipalities and in the different home care units. All nurses and patients provided written consent, which allowed us to follow the nurses during their home visits.

\section{Results}

The characteristics of both researchers' notes appeared quite similar. The notes were typically written in full sentences and contained between 35 and 45 sentences on each side of the paper; one researcher had a 16-page report and the other had an 18-page report, both on single-spaced pages. The 16-page field notes tended to have more sentences per page; therefore, the field notes were approximately the same length. Both sets of notes described the context, date, and time similarly. The contexts were described as 
morning reports at the nurses' headquarters or following the nurses on their visits to different patients' homes. Each home visit was labeled as "Visit 1", "Visit 2", and so on. The actual date and, to some extent, the time of the day and how many hours the researcher spent in the field each day were also documented. During the observation period, both researchers' notes changed from initially being extensive, where in-depth cases were presented, to becoming shorter statements in the end. The text also changed from full sentences to short notes, similar to keywords or reminders, as illustrated below:

She tells that she is going through all the patients for the purpose to become familiar with the patients she will visit that day ... Yet she brings with her a paper-list with names of all the patients she will be visiting this morning. [B, p 1]

Medication list in the living room on the shelf. Getting injection. The nurse logs out. Looking at her list on PDA.

[A, p 10]

The analysis revealed two overall findings regarding the notes' contents: 1) variety in focus and 2) differences in the analytical level.

\section{Variety in the field notes' focus}

The variety in focus means that either the nurse or the patient was in the foreground in the notes. However, the foreground/ background perspective was not equally prominent for the two researchers.

In the sociologist's notes, the patient was in the forefront in the beginning of the descriptions. The patients were often described using value-laden terms and were allotted much space in the notes:

Big lady in a wheelchair. Has lived here for two years.

Talking all the time about how hungry she is. [A, p 11]

Driving home to elderly lady with big hair in very messy apartment. [A, p 1]

However, throughout the notes, there was a movement from patient descriptions to more descriptions of the nurses' activities and addressing the study's main focus:

Nurse L is measuring the blood sugar and gives insulin, which is made a few times a week? Spread butter on a slice of bread and make sure she takes her tablets. [A, p 17]

One user shall have a new medication. Prevention of urinary tract infection. One tablet morning and evening. He has got a huge bottle of pills. M [the nurse] must send a notice of change so it can reach the next multi-dose. Originally, this medication was initiated from the home care nurses who called the general practitioner, who in turn faxed the pharmacy. [A, p 12]

The nurse researcher attempted to a greater extent to adhere to the study's focus from the start of the field notes. Her notes initially contained a short contextual description of the patient and then moved on to describe the nurses' actions:

We come to a woman. The nurse measures the patient's blood sugar and writes the result in a book lying on the kitchen workbench. On the way out and back to the car, she also writes on the PDAs. According to the nurse, she writes down measure of blood sugar. Thereafter, she sends it to the main record. [B, p 4]

The nurse researcher's focus was relatively consistent throughout the notes. The description of the nurses' interactions with other providers eventually became more prominent.

\section{Differences in the analytical levels of the field notes}

The most striking difference between the two researchers was the analytical levels of the field notes. The sociologist's notes generally consisted of plain descriptions of context, activities, and conversations:

Visit 1: She gives the patient's her pills + empties the trash for her. In the procedures/working list, it says that she [the nurse] has to empty the garbage. Writing report immediately while she [the nurse] leaves her home. Record only one line about what she has done. And update her working list [A, p 1]

The sociologist's use of plain descriptions may be interpreted as an effort to take a naïve approach to the field and note what happened. She also used examples throughout the field notes. The illustration below is an example of naïve descriptions and of using cases in the notes:

Case/example: lady with drainage. Woman had gall bladder removed and came home from the hospital the day before. There was a mistake and they cut the bile duct. Nurse will now check the drain and clear the drain. The patient tells the nurse that she must write on a form the amount of fluid she has drained from the drain. This should be recorded on a form that the nurse doesn't know about. [A, p 4]

The nurse researcher also used naïve descriptions of the nurses' work and activities in the patients' homes. She used a summarizing note labeled "reflections". However, as time 
passed, fewer reflections were presented. Using reflections implied that the notes were regarded as more analytical. Throughout the notes, the nurse researcher wrote eight such reflections. These reflections were on an analytical level and described the researcher's thoughts and interpretations of what had been observed and represented an understanding of her focus in data collection:

When studying home care nurses' information practices, it is necessary to focus on information exchange within the community of nursing service. Much communication seems to happen while they are visiting the patient. Today, I observed that they needed information that they did not have available, for example, the patient would know who would come to visit her after lunch, or when a patch was going to be replaced. [B, p 2]

In summary, both researchers fluctuated between plain and naïve descriptions combined with reflections. However, the genres varied in their descriptions of context and cases. In addition, the focus during the observations differed between the two researchers.

\section{Discussion}

Both researchers' notes were characterized along a naïveto-analytical axis. However, the focus in their notes and the extent to which different genres were used throughout the notes differed between the two researchers. The departure for our discussion is the finding of differences, which will be discussed from three main angles. The first angle is what we call "from different backgrounds", meaning our different disciplines and lenses. The second is the angle of the researchers' experience with field studies. The third angle is the nature of the notes. The notes changed in their characteristics and content throughout the observation phase, which we characterize as "from extensive to pointed notes".

\section{From different backgrounds}

The notion that we are never free of interpretive perspectives $^{9}$ implies that the researcher's professional and personal worldviews influence what is considered to be interesting enough to write in the field notes. ${ }^{12}$ Even if the notes initially appeared to be quite similar, differences were identified. The notes represented a continuum of levels from naïve or plain descriptions to analytical in their nature. The nurse researcher's notes appeared to be more analytical than the sociologist's. Instead of discussing the differences from the perspective of their belonging to different scientific positions, we found it more fruitful to take a stance in which we elicit and reflect upon the findings from the perspectives from which we come.

The nurse researcher was aware of her nursing background; therefore, she tried to avoid using value-laden statements regarding the patients. She had a general idea of how the patients might appear before entering the field and was aware of the situations she might encounter during the home visits. Through her education and practice, she had been socialized by professional readings, practical experiences, and ethical guidelines regarding how to approach ill and disabled individuals and was aware of the expressions nurse professionals use to describe them. ${ }^{22,23}$ A researcher's awareness of one's preconceptions is of importance when taking field notes. ${ }^{24}$ In this study, the nurse researcher tried to balance her nursing background with her research interests. The fluctuation between the various identified analytical levels in her notes illustrates her challenges of being a descriptive observer. She did not fully manage to transcend her nursing background and jumped to conclusions too early in the process. ${ }^{8}$

The sociologist, having been trained to enter the field with an open mind and not to limit herself to only a predefined research question, ${ }^{25}$ took notes that demonstrated that she had developed a method of writing notes that we characterize as naïve descriptions. Naïve descriptions "may be interesting, informative and serve as useful data". ${ }^{8}$ Even if naïve descriptions indicate an attempt to maintain a distance between the observer and the field, they do not represent a pure description of the field. ${ }^{8}$ The sociologist's notes reflected her interpretations and personal attitudes and alternated between impressionistic and plain descriptions.

Our findings actualize the advantages of entering the same field with different lenses. First, the differences in foci and descriptions that we identified throughout the field notes create the possibility for richer data in a research project when more than one researcher enters the field. Furthermore, these differences enable valuable discussions between researchers with different backgrounds about their interpretations of the data.

\section{From different experiences}

Atkinson notes that differences between novice and experienced field researchers are not unusual. ${ }^{26}$ Whereas inexperienced researchers often record their observations diligently, an experienced researcher often finds it more difficult to record fully. The sociologist's notes initially contained more descriptions about the patients, whereas the nurse researcher's notes addressed the nurses' work and actions. On the 
other hand, their note structures, lengths, visual appearances, and contents were quite similar.

This finding is both interesting and surprising. It is surprising that two researchers, one experienced and one inexperienced, produced such similar structures in their notes. The inexperienced nurse researcher, who was the novice in our study, had to base her methodological approach on field studies in the literature.

The sociologist's long experience as a field researcher made her aware of the common practice of using statements and value-laden expressions combined with naïve descriptions. She used this approach consciously for two distinct reasons. First, personal characteristics are useful for better remembering particular situations. Silverman emphasizes that the greatest danger is that the researcher will seek to report "everything" in their notes. ${ }^{27}$ The transformation from the field note to the use of more plain statements represents an illustration of how an experienced observer reconstructs reality. ${ }^{26}$ Second, using such statements implied the ethical consideration of maintaining the patient's anonymity in case the notes should be lost during the field observation.

The nurse researcher experienced situations that were surprising from a professional standpoint or provoked thoughts that went beyond the scope of the study. She became unsure of how to manage the unexpected and occasionally, from a nursing perspective, thought-provoking situations. She decided quite early in the process to distinguish between two main categories in her notes: 1) what she regarded or interpreted during the observation as being within the study's scope and 2) separate reflections or notes about feelings that occurred during the field study. She used this strategy to clear her mind of the signs and situations that could prevent her from being open and attentive to occurrences regarding the nurses' information practices in the field. Her reflections may also be interpreted as confessional tales. ${ }^{17}$ Choosing a strategy of organizing the notes into two main categories may have resulted in her notes being more analytical than those of the sociologist.

However, we are still left with an unanswered question: how did the inexperienced researcher, taking field notes for the first time, write notes that were similar to those of the experienced researcher? This question will remain unanswered for future investigations in which more than two researchers representing other fields are involved.

\section{From extensive to pointed notes}

The characterizations and content of the field notes changed during the data collection period and during the observation period for both researchers. Typically, field notes are written during studies in which the observations and writing of field notes last for months. Our observations were conducted over an 8-month period in one specific context. It is well known that spending a long time in the same field and context can eventually blind the researchers to seeing new things. In one of the reflection notes, the characterization of the field was described as being repetitive in rhythms and activities. Another explanation of the identified changes in the notes is that data saturation was reached or that the researchers became more efficient in their note-taking. ${ }^{7,28}$

The findings should be interpreted in light of the fact that the identified genre, structure, and resizing of the field notes also have something to do with the nature of recording observations in a specific field. The roles of researchers in home health care are analogous to balancing on a tightrope. Our balance was, on the one hand, to maintain sufficient distance to sort the important information from the unimportant information and, on the other hand, to be sufficiently involved to experience relevant situations that highlight the study's focus. The study took place in the patients' homes. The home is considered a private space, and it represents a place of safety and freedom for the resident. ${ }^{29}$ We occasionally felt that we were burdening the patients by intruding into their lives during vulnerable and difficult health and life situations. Therefore, it was difficult to remain detached, and we were not able to withdraw from the situation. Many patients treated us as their guests and wanted to include and involve us in their situations and everyday lives. Thus, the environment and involvement impacted our ability to take plain descriptive notes. This conflict represented an ethical issue; we were torn between the different roles of researchers and emotionally involved human beings. ${ }^{30}$

\section{Methodological considerations}

The identified similarities should be interpreted considering the two observers had several discussions prior to entering the field. For example, both used mostly complete sentences. However, the change identified throughout the notes regarding focus implies that we were not actively aware of the experiment during the course of our observations. The chosen approach aimed to provide data for investigating and reflecting upon whether different lenses would impact the notes taken. Trustworthiness could have been strengthened by including more researchers representing a broader professional background in the study. This was not feasible within the current project's available resources. But, for ensuring the study's credibility, we have tried to make all the phases 
of the study transparent and in particular to clarify each researcher's background and reflection throughout the entire research process. ${ }^{24}$ In addition, the researchers could have left the interpretation of all the data to others.

The study's strength, however, was the use of a researcher who conducted the main analysis but who had not been involved in any preparations and was not informed about the background of the researchers throughout the process of analyzing the notes. This approach was chosen to avoid bias from the researchers who conducted the field study.

\section{Conclusion}

The analysis revealed that different research lenses impact the focus and analytical level of the field notes, even if the structures of the notes exhibit similar characteristics. Our findings contribute new insights concerning the execution of interdisciplinary observational studies. Conducting such studies - entering the same field with different lenses allows for the production of richer as well as more varied data from a specific study setting. It enables a broader platform from which to discuss and interpret a study's findings.

From a theoretical point of view, our analysis showed that, independent of the similarities and differences in the notes' characteristics, a fluctuation between different epistemological positions was apparent in both researchers' notes. Hence, this study's findings help to guide future studies to reflect on the implication of observing and taking field notes when entering the field with different lenses. On a practical level, the findings show that even if the researchers agree on what the overall focus in the observations should be, differences can occur in both their focus and analytical level throughout the study.

\section{Acknowledgments}

We thank Hanne Marie Rostad, RN, MNSc and Linda Aasvangen, MSc for their contribution to the organization and preparation of these field notes for analysis. The present project was funded by Grant 196365/V50 from The Research Council of Norway.

\section{Disclosure}

The authors report no conflicts of interest in this work.

\section{References}

1. Klein JT. Evaluation of interdisciplinary and transdisciplinary research: a literature review. Am J Prev Med. 2008;35(2 Suppl):S116-S123.
2. Clarke D, Hawkins R, Sadler E, et al. Interdisciplinary health research: perspectives from a process evaluation research team. Qual in Prim Care. 2012;20(3):179-189.

3. Garland DR, O'Connor MK, Wolfer TA, Netting FE. Team-based research notes from the field. Qual Soc Work. 2006;5(1):93-109.

4. Reich SM, Reich JA. Cultural competence in interdisciplinary collaborations: a method for respecting diversity in research partnerships. Am J Community Psychol. 2006;38(1-2):51-62.

5. Crow GM, Levine L, Nager N. Are three heads better than one? Reflections on doing collaborative interdisciplinary research. Am Educ Res J. 1992;29(4):737-753.

6. Creswell JW. Research Design. Qualitative, Quantitative, and Mixed Methods Approaches. 4th ed. Thousand Oaks, CA: Sage; 2014.

7. Patton QM. Qualitative Research and Evaluation Methods. 3rd ed. Thousand Oaks, CA: Sage; 2002.

8. Tjora AH. Writing small discoveries: an exploration of fresh observers' observations. Qual Res. 2006;6(4):429-451.

9. Peshkin A. Angles of vision: enhancing perception in qualitative research. Qual Inq. 2001;7(2):238-253.

10. Wolfinger NH. On writing fieldnotes: collection strategies and background expectancies. Qual Res. 2002;2(1):85-93.

11. ten Have P. Understanding Qualitative Research and Ethnomethodology. London: Sage; 2004.

12. Mulhall A. In the field: notes on observation in qualitative research. J Adv Nurs. 2003;41(3):306-313.

13. Denzin NK, Lincoln YS, editors. The SAGE Handbook of Qualitative Research. 4th ed. Thousand Oaks, CA: Sage; 2011.

14. Robson C. Real World Research: A Resource for Social Scientists and Practitioner-Researchers. 3rd Ed. Oxford: Blackwell; 2011.

15. Fangen K. Deltagende Observasjon [Participant Observation]. Bergen: Fagbokforlaget; 2010. Norwegian.

16. Emerson RM, Fretz RI, Shaw LL. Writing Ethnographic Fieldnotes. 2nd ed. Chicago: The University of Chicago Press; 2011.

17. Van Maanen J. Tales of the Field: On Writing Ethnography. 2nd ed. Chicago: The University of Chicago Press; 2011.

18. Munhall PL. Nursing Research: A Qualitative Perspective. 5th ed. Sudbury, MA.: Jones and Bartlett Learning, LLC; 2012.

19. Tjora AH. Kvalitative Forskningsmetoder i Praksis [Qualitative Research Methods in Practice]. 2nd ed. Oslo: Gyldendal Akademisk; 2012. Norwegian.

20. Hammersley M, Atkinson P. Ethnography: Principles in Practice. 3rd ed. London: Routledge; 2007.

21. Malterud K. Kvalitative Metoder i Medisinsk Forskning: En Innføring. [Qualitative Methods in Medical Research: An Introduction] 2nd ed. Oslo: Universitetsforlaget; 2003. Norwegian.

22. Kim HS. The Nature of Theoretical Thinking in Nursing. 3rd ed. New York: Springer Publishing Company, LLC; 2010.

23. Meleis AI. Theoretical Nursing: Development and Progress. 5th ed. Philadelphia, PA: Wolters Kluwer Health, Lippincott Williams \& Wilkins; 2012.

24. Polit DF, Beck CT. Nursing Research: Generating and Assessing Evidence for Nursing Practice. 9th ed. Philadelphia, PA: Wolters Kluwer Health, Lippincott Williams \& Wilkins; 2012.

25. Law J. After Method: Mess in Social Science Research. London: Routledge; 2004.

26. Atkinson P. Understanding Ethnographic Texts. Newbury Park: Sage; 1992.

27. Silverman D. Doing Qualitative Research. A Practical Handbook. 3rd ed. London: Sage; 2010.

28. Kvale S, Brinkmann S. Det Kvalitative Forskningsintervju [The Qualitative Research Interview]. 2nd ed. Oslo: Gyldendal Akademisk; 2009. Norwegian.

29. Douglas M. The idea of a home: a kind of space. Soc Res (New York). 1991;58(1):287-307.

30. Silverman D. Interpreting Qualitative Data: Methods for Analyzing Talk, Text and Interaction. 5th ed. London: Sage; 2014. 


\section{Publish your work in this journal}

The Journal of Multidisciplinary Healthcare is an international, peerreviewed open-access journal that aims to represent and publish research in healthcare areas delivered by practitioners of different disciplines. This includes studies and reviews conducted by multidisciplinary teams as well as research which evaluates the results or conduct of such teams or healthcare processes in general. The journal covers a wide range of areas and welcomes submissions from practitioners at all levels, from all over the world. The manuscript management system is completely online and includes a very quick and fair peer-review system. Visit http://www.dovepress.com/testimonials.php to read real quotes from published authors.

Submit your manuscript here: http://www.dovepress.com/journal-of-multidisciplinary-healthcare-journal 